\title{
Texto de revista impressa de negócios: modos de argumentar'
}

\section{Cleonice Men da Silva Ramos}

- Doutoranda pela Universidade de São Paulo no curso de Letras, área de Filologia e Língua Portuguesa

- Mestre pela Universidade de São Paulo na área de Semiótica e Linguística Geral

- Graduada em Letras e pós-graduada lato sensu em Português, Língua e Literatura

- Participante do Grupo de Estudos de Retórica e Argumentação (GERAR) da USP

- Desenvolve pesquisas que abrangem estratégias argumentativas e efeitos de sentido em revistas impressas da esfera social de negócios, economia e administração

- Atua na área corporativa há mais de 25 anos assessorando presidentes e diretores

- cleonicemen@usp.br

-men.ramos@uol.com.br

1 As análises que compõem esta pesquisa são desenvolvimentos preliminares de minha tese de doutorado no programa de pós-graduação em Filologia e Língua Portuguesa da Faculdade de Filosofia, Letras e Ciências Humanas da Universidade de São Paulo (FFLCH-USP), em andamento, sob orientação da profa. Dra. Lineide do Lago Salvador Mosca. 
Esta pesquisa objetiva mostrar estratégias argumentativo-persuasivas e os efeitos de sentido delas decorrentes ao analisar o texto capa de revista impressa do universo discursivo corporativo-empresarial. A importância de recuperar efeitos argumentativos em textos midiáticos da atualidade justifica-se porque não se argumenta apenas para obter consenso sobre algum ponto de vista divergente, mas também para reforçar crenças e valores radicados em um indivíduo ou em um grupo específico; argumenta-se, enfim, mediante um discurso eficaz para persuadir o outro, conquistar sua adesão.

PALAVRAS-CHAVE: ESTRATÉGIAS ARGUMENTATIVO-PERSUASIVAS • UNIVERSO DISCURSIVO CORPORATIVO-EMPRESA-

RIAL・REVISTA IMPRESSA DE NEGÓCIOS • TEXTO CAPA • EFEITOS DE SENTIDO

\section{Abstract}

This paper aims at showing argumentative/persuasive strategies and their resulting meaning effects by analyzing the "cover" text of a printed magazine from the corporate business discursive sphere. The importance of recovering argumentative effects in present-day media texts stems mostly from the fact that, not only does the argumentation process serve to arrive at a consensus about some divergent point of view, but also it strengthens beliefs and values that are deeply rooted in an individual or in a group; in short, to ensure the audience's adherence through an effective speech: thereby persuading others.

KEYWORDS: ARGUMENTATIVE/PERSUASIVE STRATEGIES - CORPORATE BUSINESS DISCOURSE • PRINTED BUSINESS

MAGAZINE • "COVER" TEXT • MEANING EFFECTS

Resumen

El objetivo de esta investigación es mostrar las estrategias argumentativo-persuasivas y los efectos de sentido resultantes de ellas al analizar el texto portada de una revista impresa que pertenece al universo discursivo corporativo-empresarial. La importancia de recuperar los efectos argumentativos en textos de los medios actuales se justifica porque no se argumenta solamente para llegar a un consenso sobre un punto de vista divergente, sino también para reforzar las creencias y los valores arraigados en un individuo o en un grupo específico; se argumenta, en fin, por medio de un discurso eficaz para persuadir al otro, conquistar su adhesión.

PALAVRAS CLAVE: ESTRATEGIAS ARGUMENTATIVO-PERSUASIVAS • UNIVERSO DISCURSIVO CORPORATIVO-EMPRESA-

RIAL・REVISTA IMPRESA DE NEGOCIOS • TEXTO PORTADA • EFECTOS DE SENTIDO 
A rgumentamos, sempre, de forma instintiva ou intencional. Argumentamos bem quando bem conhecemos mecanismos apropriados. Argumentamos melhor quando conhecemos com quem argumentamos. Para isso especificamente, fazemos escolhas discursivas, marcamos presença e celebramos comunhão em estreita interação comunicacional.

A circulação de discursos por meio da mídia jornalística impressa voltada à esfera de negócios enseja processos argumentativos pertinentes e inevitavelmente presentes na produção textual. Pelos estudos retórico-argumentativos empreendidos atualmente, em especial em uma comunicação dirigida a um público-alvo, torna-se evidente que nenhum processo argumentativo jamais se funda no "vazio". Pelo contrário, invariável e intencionalmente, ele apresenta um propósito, planejado por um "eu” que busca persuadir um "outro" sobre determinado ponto de vista divergente, posto em discussão ou, ainda, defender e fortalecer uma tese pretensiosamente tomada como aceita.

Com o objetivo de verificar mecanismos argumentativos envolvendo parceiros discursivos em interação, foi eleito e recortado para análise o texto capa da revista impressa da área de negócios EXAME. Tratemos de discorrer sucintamente sobre a revista de publicação nacional. A EXAME, da Editora Abril, de circulação quinzenal, foi lançada no Brasil em julho de 1968 como caderno especial de economia, finanças e administração, tendo-se tornado publicação autônoma em 1971.

Os recursos teórico-metodológicos adotados nas análises serão os da Nova Retórica, especialmente considerando preceitos e nomenclaturas de Perelman e Olbrechts-Tyteca oriundos do Tratado da argumentação: a nova retórica (2005); os da Semiótica, que, pelos seus modelos e atributos, primam por rigor e solidez, tendo-se fortalecido e proposto metodologias eficazes que buscam efeitos de sentido a depreender; os da Análise do Discurso, cujas produções verbais do discurso nos sistemas linguísticos, com suas nomenclaturas e definições afins em estreita interação com a Semiótica -, são de fundamental importância.

Considera-se a revitalização da Retórica e da Nova Retórica na atualidade e a consolidação de sua importância nos estudos dos mais distintos textos. Certa relevância dos estudos dos preceitos teóricos em correlação aos da Semiótica tem sido, do mesmo modo, considerada. As pesquisas da Semiótica empreenderam recentemente um retorno em direção à Retórica e à Nova Retórica, visando, notadamente, à observação das estratégias argumentativo-persuasivas em um discurso tido como eficaz. Uma proposta de correlação entre essas disciplinas vem sendo defendida por estudiosos da área, como afirma Lineide Mosca: "apesar de a Semiótica ter-se mantido afastada da Retórica, as duas disciplinas têm-se voltado para o mesmo tipo de fenômenos” (2004, p. 25).

Ao proceder a certas correlações dessas disciplinas neste trabalho, respeitaramse os preceitos de cada uma, o que demandou posicionar-se, a priori, sobre as 
definições e terminologias envolvidas. Ciente das diferenciações do discurso oral vs escrito e considerando que o discurso das revistas se manifesta em mídia impressa, veiculado, portanto, no suporte material papel, a nomenclatura do orador, como a Retórica denomina aquele que discursa de viva voz diante de uma plateia, será aqui tomada de forma correlata, porém obedecendo à especificidade pertinente à forma do discurso: texto escrito. Essa nomenclatura é transposta para aquele que discursa, que enuncia, por meio impresso.

Enunciador e enunciatário-(leitor) são terminologias da Semiótica do nível discursivo do percurso gerativo de sentido, modelo teórico-metodológico proposto pelo pesquisador lituano Algirdas Julien Greimas. É o nível discursivo o lugar para a argumentação persuasiva, aquela em que um sujeito leva outro à ação: fazer-crer para fazer-fazer. Dotado de três níveis - fundamental, narrativo e discursivo -, o percurso, ao reconstruir o sentido do plano do conteúdo dos textos, constitui um dos pilares dos estudos semióticos de vertente francesa.

No quadro teórico da Semiótica, o texto é tomado nas relações de oposição de sentido que o constituem, das quais a primeira é a oposição "expressão/ conteúdo": "como signo, o texto apresenta um plano da expressão e um plano do conteúdo: aquele veicula este", diz Discini (2005, p. 345), ao sintetizar a tradição teórica da Semiótica. Essa teoria chama de sujeitos semióticos aqueles cujas imagens são construídas no discurso. Sujeitos pressupostos no discurso, enunciador e enunciatário-leitor configuram duas instâncias do discurso, constituindo simulacros do autor (produtor/emissor) e do leitor (destinatário/receptor) criados pelo texto.

Nos preceitos semióticos, é a voz discursiva que está por trás de qualquer discurso que importa, ou seja, a voz do enunciador (produtor do discurso) de um texto/discurso. Essa importância recai sobre seu enunciatário-leitor, já que este se configura na imagem daquele. Na teoria retórica, a imagem do auditório é, do mesmo modo, de ímpar consideração. A nomenclatura orador/auditório não é somente utilizada na teoria retórica clássica, mas também por Perelman e Olbrechts-Tyteca ao longo do Tratado (2005). Esses autores utilizam ainda as denominações ouvintes ou pessoas.

Desde os ensinamentos aristotélicos, postula-se que a argumentação eficaz requer um acordo prévio entre o orador e seu auditório. Perelman e Olbrechts-Tyteca, com esses ensinamentos, ratificam que, "do princípio ao fim, a análise da argumentação versa sobre o que é presumidamente admitido pelos ouvintes” (2005, p. 73). Tal acordo é especialmente firmado com um auditório tomado como particular. O conceito de auditório particular, tão caro a Perelman e Olbrechts-Tyteca, é importante neste trabalho, uma vez que assim o vemos configurado na revista ora em análise. De construção mais ou menos sistematizada, esse auditório é mantido pelo enunciador tão próximo quanto possível da realidade. O orador constrói seu discurso (lógos) respondendo a uma imagem desse auditório ( $p a ́$ thos), sob uma determinada doxa, fazendo coexistir uma interação comunicacio- 
nal de aceitação mútua de crenças e valores. Vê-se, desse modo, um ponto de encontro de um "eu" com um "outro", sujeitos que se identificam e se constituem reciprocamente, configurando uma adesão dos espíritos, para usar os termos de Perelman e Olbrechts-Tyteca (2005), autores para quem, em um auditório particular, a argumentação, produzida em maior grau pelo racional e emocional, tem a pretensão de levar à persuasão; em um auditório universal, em maior grau pelo racional, ao convencimento. Assim, a retórica hoje, notadamente se direcionada ao ato comunicativo num auditório particular em que sujeitos sociais interagem em distância reduzida, é tomada como um instrumento de persuasão.

\section{Análise}

A edição de n. 929 da EXAME, de 22 de outubro de 2008, veio a público em tempos de plena crise mundial financeira/econômica, crise associada ao estouro da bolha imobiliária nos Estados Unidos e às operações da bolsa de valores. Vejamos a figura da capa, texto a ser analisado:

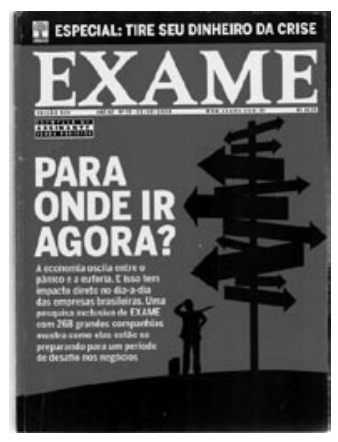

Fig. 1 - Capa EXAME, ed. 929, de 22/10/2008

A capa reflete informações prioritárias da revista: é para ela o primeiro olhar do leitor em busca do que há de mais importante na edição veiculada. Como parte indissociável de uma edição, esse texto faz o chamamento ao enunciatário-leitor: estampa o tema eleito de importância, a ser desenvolvido na reportagem de capa, outro texto privilegiado da revista. Os elementos constituintes predominantes desse texto são, usualmente, fotos, desenhos, símbolos ou ainda caracteres tipográficos. A capa é considerada texto sincrético, já que traz recursos advindos da união das linguagens verbal e visual, com prevalência do uso da segunda.

Marcas de presença e de comunhão com o auditório

Em uma análise da linguagem verbal, observemos a pergunta retórica que aparece na capa: “PARA ONDE IR AGORA?". Esse enunciado interrogativo é 
o chamamento para a leitura da reportagem de capa. Falemos dos efeitos argumentativos da pergunta retórica. O orador (enunciador) pergunta, buscando comprometimento com seu auditório (enunciatário-leitor), pondo-o em interação no ato comunicativo. A pergunta retórica marca um "diálogo" apenas encetado: é o próprio enunciador quem vai responder à pergunta feita.

Perelman e Olbrechts-Tyteca ensinam que "a forma interrogativa não deixa de introduzir um apelo à comunhão com um auditório, ainda que este fosse $o$ próprio sujeito" (2005, p. 180). Essa interpelação à atenção do outro, mesmo que de modo indireto, torna, assim, a pergunta retórica uma figura argumentativa de comunhão. Delineia-se a estreita relação e a efetiva aproximação entre os parceiros no ato comunicativo.

Ainda destacando a linguagem verbal, outro enunciado, acima do logotipo EXAME, grafado em branco com fundo preto, destaca: "ESPECIAL: TIRE SEU DINHEIRO DA CRISE”. Observa-se o uso do imperativo no enunciado, característica do tipo textual injuntivo, o que dita regras de como fazer. Mesmo sendo assimétrica a relação com o enunciador que sabe mais do que seu enunciatário-leitor, é marca de interação fortalecida entre eles no ato de comunicação. O auditório espera essa regra de como fazer. É um "ensinamento” a ser aprendido: como fazer para "tirar seu dinheiro da crise". A "lição" é aceita pelo enunciatário-leitor porque houve acordo prévio firmado.

Com o tipo textual injuntivo e a direta interpelação no tempo presente, temos o que Perelman e Olbrechts-Tyteca (2005) denominam aumento do sentimento de presença no discurso. Mais uma vez configura-se a estreita interação dos parceiros no ato comunicativo.

Além do enunciado chamativo com a pergunta retórica incitando a ler a reportagem de capa "PARA ONDE IR AGORA?", a capa traz um fragmento textual complementar, grafado em branco num fundo vermelho, com tipografia de menor tamanho. Reproduzimos o trecho:

"A economia oscila entre o pânico e a euforia. E isso tem impacto direto no dia a dia das empresas brasileiras. Uma pesquisa exclusiva de EXAME com 268 grandes companhias mostra como elas estão se preparando para um desafio nos negócios."

Nesse fragmento textual, nosso olhar analítico direciona-se ao índice quantitativo: "268 grandes companhias". Tratemos desse índice, tomado como lugar da quantidade.

Lugar da quantidade: objeto de acordo argumentativo

Uma definição geral advinda dos preceitos aristotélicos na Retórica clássica é que tópicos ou lugares (topoi) se referem a fontes de argumentação que podem 
servir de premissas para silogismos dialéticos ou retóricos. Aristóteles fazia, contudo, distinção entre lugares-comuns e lugares específicos. Os primeiros, com estoques de argumentos utilizáveis a qualquer ciência; os segundos, os aplicáveis em ciências específicas ou em gênero oratório definido. Para Reboul (2004, p. 51) "o lugar é um argumento pronto que o defensor pode colocar em determinado momento de seu discurso". Na Nova Retórica, Perelman e Olbrechts-Tyteca (2005, p. 96) classificam de importantes, pela prática argumentativa em todos os auditórios, os itens bastante gerais: "lugares da quantidade, da qualidade, da ordem, do existente, da essência, da pessoa”. Os autores, em consonância com os preceitos aristotélicos, entendem por lugares da quantidade "os lugares-comuns que afirmam que alguma coisa é melhor do que outra por razões quantitativas” (PERELMAN; OLBRECHTS-TYTECA, 2005, p. 97).

Como já dito, a capa é considerada um texto sincrético, ou seja, dotado das linguagens verbal e visual. Relembremos, do verbal, a pergunta retórica que nela aparece: "Para onde ir agora?". Da linguagem visual, vemos os elementos figurativos do plano da expressão: muitas setas apontando para direções diferentes e a figura de um suposto executivo de mão na cabeça, gravata esvoaçando em desalinho, contrariando o ícone da vestimenta do executivo: terno e gravata alinhados com esmero. Com as duas linguagens (verbal e visual) sincretizadas, depreende-se o efeito de sentido de desorientação "para onde ir agora?". A fim de orientar-se e descobrir "para onde ir agora", deve o executivo considerar a "pesquisa exclusiva de EXAME com 268 grandes companhias [na qual] mostra como elas estão se preparando para um período de desafio nos negócios”.

A força argumentativa do orador (enunciador) para esse direcionamento está apoiada no lugar da quantidade: São 268 grandes empresas que fizeram parte da "pesquisa exclusiva de EXAME”. O número, consideravelmente alto, garante maior probabilidade de acerto para o enunciatário-leitor - tomado como sujeito executivo individualizado atuante em uma empresa - preparar-se "para um período de desafio de negócios". Com esse tipo de objeto de acordo na capa - texto do primeiro olhar -, o lugar da quantidade transforma-se em ponto de partida da argumentação, fortalecendo a crença no discurso do enunciador pela "superioridade do que é admitido pelo maior número" e ainda - como afirmam Perelman e Olbrechts-Tyteca - pela maior probabilidade de acerto, já que "podemos considerar como lugares de quantidade a preferência concedida ao provável sobre o improvável” (2005, p. 99). Com a crença fortalecida no discurso pelo objeto argumentativo, o enunciador marca sua persuasão enunciativa, levando o enunciatário-leitor à ação, isto é, à leitura da pesquisa na reportagem de capa para saber "para onde ir agora".

Toma-se ainda para análise, como texto extensivo da capa, a figura que aparece na página 08 dessa mesma edição. Essa página, que faz chamadas para o enunciatário-leitor acessar o "Portal EXAME", repete o visual da capa, alterando somente a linguagem verbal. Em destaque, com tipografia maior e em caixa alta lê-se outra pergunta retórica: "PARA ONDE VAI A BOLSA?". O 
direcionamento não é mais o da capa, cuja pergunta retórica - relembremos dirigia-se ao executivo/ empresas: "PARA ONDE IR AGORA?". Novamente, a força argumentativa está posicionada no lugar da quantidade. Diz o fragmento abaixo do título "PARA ONDE VAI A BOLSA?": "A ação coordenada de socorro a bancos em diversos países da Europa e a capitalização das instituições financeiras dos Estados Unidos geraram euforia no mercado". Citemos já o índice "diversos países". Segue o enunciado que encerra o fragmento textual: "Somente um dos oito analistas consultados pelo Portal EXAME, porém, arriscou dizer que o pior da crise já passou. Veja as opiniões". Observa-se o uso indireto do lugar da quantidade: se somente um dos oito analistas consultados arriscou dizer que o pior da crise já passou, restam sete analistas que consideram que o "pior da crise [ainda não] passou”.

Ao tomar os pólos realçados no discurso da capa, "pânico e euforia”, que definem o momento oscilante da economia, temos - com a utilização do lugar da quantidade e com o apoio de vozes que detêm o argumento de autoridade (os analistas consultados) - um discurso argumentativo mais posicionado no polo disfórico da crise, contrário ao polo eufórico afirmado no fragmento: "A ação coordenada de socorro a bancos em diversos países da Europa e a capitalização das instituições financeiras dos Estados Unidos geraram euforia no mercado”. Os lexemas "somente" e "porém" ratificam a contrariedade discursiva. Recuperemos o enunciado que encerra o fragmento textual: "Veja as opiniões". Esse enunciado no imperativo volta a mostrar que aumenta o sentimento de presença com o auditório. O enunciador interpela mais uma vez o enunciatárioleitor, "guiando-o", incitando-o à ação: ir à leitura das opiniões de analistas no Portal EXAME para comprovar o posicionamento discursivo disfórico.

As vozes dos analistas são consideradas como argumento de autoridade. O uso que faz o enunciador dessas vozes de prestígio na temática apropriada enriquece sua força discursiva argumentativa. Baseado na estrutura do real, o argumento de autoridade, como se posicionam Perelman e Olbrechts-Tyteca, "em vez de constituir a única prova, vem completar uma rica argumentação" (2005, p. 350). A citação dessas vozes é a estratégia argumentativa do enunciador e contribui para aumentar o efeito de verdade, valioso ao discurso jornalístico. Esse efeito vai gerar maior credibilidade discursiva, igualmente inestimável.

\section{Para além da linguagem verbal: o semi-simbolismo}

Ao tratar do visual cromático, adentra-se na relação simbólica, ou seja, dimensão cultural relacionada às cores. O fundo da capa (cf. fig. 1) é quase todo vermelho, com uma estreita base preta representando a superfície em que pisa a figura do suposto executivo. A cor vermelha no Ocidente sugere calor, fogo. Assim é depreendido, interpretado e aceito culturalmente, por isso, simbólico. Guimarães (2004, p. 80) afirma que os tons vermelhos e amarelos estão relacionados a elementos de "aquecimento, fogo e sol". 
Para além da simbologia cromática, com apoio no quadro teórico da Semiótica, adentremos, com a estrutura cromática, no semissimbolismo. Os elementos do visual que aparecem na capa, figuras do plano da expressão, são denominados formantes plásticos. Isotopicamente, confirmam na capa o universo temático que já se prenuncia em primeira mão. Os formantes plásticos se dividem em três categorias: a topológica (ligada às posições); a eidética (ligada às formas); a cromática (ligada às cores). Haverá relação semissimbólica quando uma categoria do significante (expressão) se relacionar, por homologação, com outra do significado (conteúdo). Em outras palavras, o sentido será formado por correlações entre as categorias dos dois planos: expressão e conteúdo.

Constata-se, na capa, o vermelho como cromatismo do plano da expressão, que, homologado com uma figura do discurso "pânico", depreende o efeito de sentido de excitação negativa: é a "desorientação" na economia, com grandes empresas que "estão se preparando para um período de desafio”. Na área financeira, "estar no vermelho" significa operar com prejuízo. O desafio então deve ser assumido pelas grandes empresas para ou não entrarem no "vermelho”, ou - aí estando - dele saírem. A figura do executivo com a mão na cabeça sugere que ele já está ou pode ficar de "cabeça quente".

O cromático ainda sobressai na capa com o branco vs vermelho/preto. Voltemos às afirmações de Guimarães: "Em oposição ao preto, o branco é a cor da vida e da paz" (2004, p. 91). Outros elementos figurativos em destaque que se deixam ver na capa são uma haste com várias setas de tamanhos diversos, todas na cor preta, apontadas para ambos os lados - direito e esquerdo. O preto, além de representar no Ocidente luto, morte e trevas, "é a cor do desconhecido e do que provoca medo” (GUIMARÃES, 2004, p. 91).

Em tamanho bem menor, abaixo das setas, está a figura do suposto executivo, uma mão na cintura e outra na cabeça, representando a gestualidade de desalento. Uma maleta quadrada, de tipo executivo, está posta no chão. Lembremos o ícone da vestimenta executiva - a gravata - aqui não assentada como determina o figurino executivo empresarial. Esvoaçante, produz um efeito hiperbólico, que, junto às setas que apontam para direções opostas, deixa visualmente discursivizada a desorientação: "para onde ir agora?".

O logotipo da EXAME e os demais enunciados grafados em branco transmitem o autocontrole para "onde ir agora", polo em oposição ao vermelho (quente) e ao preto (trevas, desconhecimento) que prenunciam o pânico. As linguagens verbal e visual se complementam para o efeito de sentido de que a economia oscila entre o pânico [fundo vermelho e elementos em preto] e a euforia [enunciados em branco]. Com todos os enunciados grafados em branco podese depreender a "frieza" associada ao autocontrole para o enunciatário-leitor se direcionar "para onde ir". O cromático no verbal, como estratégia na produção textual, tem, igualmente, força argumentativa. 


\section{Considerações finais}

Com as análises do texto de capa da revista impressa de negócios EXAME, pôde-se constatar estratégias argumentativo-persuasivas do orador (enunciador) que pretendem fazer seu auditório (enunciatário-leitor) crer no discurso e leválo à ação: ir à leitura para orientar-se sobre a temática de maior importância - a crise mundial. Um acordo para o uso e a interpretação dessas estratégias foi firmado entre os sujeitos no ato comunicativo. Centrado no ponto de partida da argumentação, desde o início esse acordo se estampa na capa, texto do primeiro olhar do leitor.

Pela linguagem verbal e com a pergunta retórica, que se traduz em figura argumentativa de comunhão, vimos delineada a plena interação entre os parceiros no ato comunicativo. $\mathrm{O}$ enunciador busca maior credibilidade no seu discurso ao citar vozes com o argumento de autoridade: os analistas. Mostramos que a argumentação do enunciador ganha força pelo uso do lugar da quantidade e, ainda, pelo tipo textual injuntivo, forma apelativa do imperativo que faz aumentar o sentimento de presença com o auditório. Com a linguagem visual e a estrutura cromática - do plano da expressão - em correlação com figuras do discurso - do plano do conteúdo - depreenderam-se efeitos de sentido relacionados às paixões (emoções) contrárias citadas: "euforia e pânico".

Considerou-se a revista EXAME beneficiada de um auditório particular. Nesse auditório, dotado de universo dóxico que lhe é caro, o enunciador é conhecedor dos valores e crenças de seu enunciatário-leitor e, assim, vê-se nele espelhada a sua própria imagem. Por constituir-se em espaço discursivo facilitador de plena adesão, o enunciador detém maior eficácia discursiva para aproximarse desse auditório, obter-lhe a adesão e mantê-la. É para tanto que se escolhem as estratégias argumentativas na produção textual: tornar crível seu discurso e fortalecer a estreita e plena interação no ato comunicativo.

\section{Referências}

DISCINI, Norma. Comunicação nos textos. São Paulo: Contexto, 2005.

EXAME. São Paulo: Abril, 2008.

GREIMAS Algirdas Julien; COURTÈS, Joseph. Dicionário de semiótica. Trad. Alceu Dias Lima et al. São Paulo: Cultrix, 1989.

GUIMARÃES, Luciano. A cor como informação: a construção biofísica, linguística e cultural da simbologia das cores. 3. ed. São Paulo: Annablume, 2004.

MOSCA, Lineide do Lago Salvador. Velhas e novas retóricas: convergências e desdobramentos. In: (Org.). Retóricas de ontem. $3^{\mathrm{a}}$ ed. São Paulo: Humanitas, 2004.

PERELMAN, Chaïm; OLBRECHTS-TYTECA, Lucie. Tratado da Argumentação. A Nova Retórica. Trad. Maria Ermantina de A. P. Galvão. São Paulo: Martins Fontes, 2005.

REBOUL, Olivier. Introdução à retórica. Trad. Ivone Castilho Benedetti. São Paulo: Martins Fontes, 2004. 